\title{
O PLANEJAMENTO PEDAgógico COMO ESPAÇO DE ESCUTA, COMPARTILHAMENTO DE SABERES E TROCAS DE EXPERIÊNCIAS
}

\author{
Ércules Laurentino Diniz D1, Larissa Cavalcanti de Albuquerque iD2
}

Edineide Jezine Mesquita Araujo iD 3 e Maria das Graças de Almeida Baptista (D)

\section{Resumo}

O artigo tem como justificativa a necessidade de refletir sobre as práticas pedagógicas, a partir dos encontros de planejamento como elemento de promover mudanças, pensar estratégias, consolidar práticas e refletir coletivamente sobre a educação pública. Como questões norteadoras do estudo, temos: refletir sobre o processo de planejamento a luz de teóricos e refletir sobre o planejamento como instrumento norteador de práticas pedagógicas. No caminho metodológico utilizamos o estudo de caso, com uso das técnicas de revisão de literatura, pesquisa documental, observação e entrevista semiestruturada, para análise dos dados seguimos os passos indicados por Yin (2016), no tocante à sistematização dos dados, composição, decomposição, interpretação e análises. Como resultados temos que os sujeitos da pesquisa apontam três problemáticas para as melhorias na escola com um todo: a participação família-escola; condições materiais e de infraestrutura e o papel das tecnologias no processo ensino-aprendizagem.

Palavras-chave: Planejamento; Formação de professores; Ensino e aprendizagem.

\section{PEDAGOGICAL PLANNING AS A SPACE FOR LISTENING, SHARING OF KNOWLEDGE AND EXCHANGES OF EXPERIENCES}

\section{Absctrat}

The article's justification is the need to reflect on pedagogical practices, based on planning meetings as an element to promote changes, think strategies, consolidate practices and collectively reflect on public education. As guiding questions of the study, we have: to reflect on the planning process in the light of theorists and to reflect on planning as a guiding tool for pedagogical practices. In the methodological path we used the case study, using the techniques of literature review, documentary research, observation and semi-structured interview, for data analysis we followed the steps indicated by Yin (2016), with regard to the systematization of data,

\footnotetext{
${ }^{1}$ Mestre pelo Programa de Pós-Graduação em Educação da Universidade Federal da Paraíba. Professor na rede estadual da Paraíba. E-mail: ercules.diniz@hotmail.com

${ }^{2}$ Mestra pelo Programa de Pós-Graduação em Educação da Universidade Federal da Paraíba. Graduada em Serviço Social pela Universidade Federal da Paraíba. Assistente social na rede municipal de João Pessoa-PB. E-mail: laalbuquerque13@hotmail.com ${ }^{3}$ Doutor em Sociologia pela Universidade Federal de Pernambuco com Pós-doutoramento na Universidade Lusófona de Humanidades e Tecnologias - Lisboa/PT (CAPES/FCT), com instância acadêmica na Universidade de Valência (Espanha, 2011). Professora Titular da Universidade Federal da Paraíba como atuação no ensino, pesquisa e extensão, na Graduação e Pósgraduação. E-mail: edjezine@gmail.com

${ }^{4}$ Doutora e Mestre em Educação pelo Programa de Pós-graduação em Educação da Universidade Federal da Paraíba (PPGE/UFPB), com Pós-doutorado em Educação pela Universidade Estadual de Campinas (UNICAMP). Professora do Programa de Pós-graduação em Educação (PPGE/UFPB), no Centro de Educação (UFPB). E-mail: gabaptista2@yahoo.com.br
} 
composition, decomposition, interpretation and analysis. As a result, we have that the research subjects point out three problems for improvements in the school as a whole: the family-school participation; material and infrastructure conditions and the role of technologies in the teaching-learning process.

Keywords: Planning; Teacher training; Teaching and learning.

\section{Introdução}

O ato de planejar é intrínseco ao ser humano, somos dotados da capacidade de antever nossas ações, pensando meios de atingir nossos objetivos. Quando pensamos a instituição escola, estamos refletindo sobre um espaço que engloba uma diversidade de sujeitos e se constitui como responsável pelo processo de escolarização formal na sociedade brasileira, em parceria com outros atores como a família e a sociedade. Diante disso, um grande aliado para promover melhorias nas práticas docentes, inovar na didática e buscar possibilidades junto aos alunos é o planejamento pedagógico.

O artigo tem como objetivo a necessidade de refletir sobre as práticas pedagógicas, a partir dos encontros de planejamento como elemento de promover mudanças, pensar estratégias, consolidar práticas e refletir coletivamente sobre a educação pública. Conforme Saviani (1997, p.23) "refletir é o ato de retomar, reconsiderar os dados disponíveis, revisar, vasculhar numa busca constante de significado. É examinar detidamente, prestar atenção, analisar com cuidado. E isto é filosofar." O objetivo geral do presente trabalho, constitui-se em refletir sobre o planejamento pedagógico como espaço de escuta dos discursos docentes, construção de saberes e compartilhamento de experiências. São objetivos específicos: realizar uma revisão da literatura sobre o tema, apresentar o ponto de vista dos docentes, bem como, investigar as críticas expostas pelos professores com relação ao processo pedagógico.

O planejamento constitui um momento de fundamental importância para os rumos do estabelecimento escolar. Membros da gestão, da secretaria e todo o corpo docente, devem, ainda antes do início do período letivo, traçar os itinerários a serem seguidos ao longo do ano, a fim de não estarem habituados aos improvisos, necessários diante das contingências, mas inadequados quando recorrentes. $E$ esse processo é algo contínuo que acompanha do processo do ano letivo. 
Contudo, os momentos dedicados aos planejamentos são negligenciados por muitos professores, seja por problemas como falta de tempo, ou de estímulo para planejar atividades que dificilmente podem ser desenvolvidas devido à falta de estrutura, o fato é que para muitos docentes, o planejamento não faz parte da rotina pedagógica. A esse respeito, Luckesi (2011) mostra-se inquieto com os episódios em que o planejamento se torna um mero preenchimento de formulários, em um contexto marcado pelo simples atendimento às demandas burocráticas.

Planejar é construir meios que tornem exequíveis as metas, tal planejamento são passos importantes no caminho que leva ao êxito da prática educativa. Abordando exclusivamente o trabalho docente, Libâneo (1994, p.221) afirma que "o planejamento escolar inclui tanto a previsão das atividades didáticas quanto a sua revisão e adequação no decorrer do processo de ensino", demonstrando, portanto, o caráter flexível que o ato de planejar deve assumir.

Tendo em vista, o trabalho em uma relação teoria e empiria, realizamos um estudo de caso, tendo como lócus uma escola que integra a rede municipal de educação de João Pessoa-PB, sendo os sujeitos da pesquisa profissionais que compõem o corpo docente, gestores e especialistas. A unidade de ensino integra o universo de 95 escolas da rede municipal, seu público-alvo constitui-se meninos e meninas da educação infantil até o $5^{\circ}$ ano, sendo que nos anos de 2018 e 2019 a escola ofertou o projeto de correção de fluxo "Acelerando Saber", voltado para os educandos com distorção idade-ano. A escola possui um total de 13 turmas, distribuídas nos turnos da manhã e da tarde, desde o ano de 2015 que a escola não oferta a educação de jovens e adultos, devido a um redimensionamento das vagas realizadas pela prefeitura.

Como questões norteadoras do estudo, temos: refletir sobre o processo de planejamento a luz de teóricos e refletir sobre o planejamento como instrumento norteador de práticas pedagógicas.

Para o alcance dos objetivos faremos uma incursão teórica sobre o planejamento pedagógico, caminhos teórico-metodológicos da pesquisa, resultados e discussões, ao final temos as conclusões e as referências que nortearam o artigo.

\section{2. $O$ ato de planejar como instrumento reflexivo}


Na escola, o ato de planejar perpassa por todos os setores, a exemplo da cozinha que prepara a merenda a partir de um cardápio que foi pensado a fim de ofertar uma dieta rica em nutrientes que são necessários para o bom desenvolvimento do educando; a secretaria que organiza os documentos da escola e as fichas dos alunos; a biblioteca que conta com a catalogação dos livros, empréstimos e devoluções. Todos os setores da escola atuam para o processo pedagógico de escolarização de crianças, adolescentes, jovens e adultos.

Segundo Haydt (2006, p. 94), o planejamento é "um processo mental que envolve análise, reflexão e previsão". Quando falamos em planejamento pedagógico, estão envolvidos os conteúdos a serem ministrados, a didática utilizada pelos professores, a avaliação e todos os fatores que perpassam o processo de ensino e aprendizagem. Indagações como: O que pretendemos obter? Em quanto tempo? Como posso obter tais resultados? Quais os recursos necessários? Como analisar a situação e identificar se os objetivos foram alcançados? São alguns questionamentos que perpassam por esse processo de planejar.

Assim sendo, de acordo com Haydt (2008) quando falamos em planejamento precisamos saber qual a concepção filosófica que rege a instituição, a fim de nortearmos os objetivos da ação educativa. Dessa forma, são definidos os critérios para a seleção de conteúdos. O planejamento escolar é um documento que indaga: onde estamos? E onde queremos chegar?

Quando se identifica o lugar que a instituição ocupa, seja em índices de reprovação e evasão, relação família e escola, em que patamar a instituição se encontra tanto em avaliação interna, como externa; podemos traçar novos planos e ações, com vistas a novas metas que propiciarão melhorias na aprendizagem dos alunos e na instituição como um todo. O professor José Carlos Libâneo nos auxilia nessa compreensão a respeito do que é planejamento:

A ação de planejar, [...] é antes, a atividade consciente de previsão das ações docentes, fundamentadas em opções político-pedagógicas, e tendo como referência permanente as situações didáticas concretas (isto é, a problemática social, econômica, política e cultural que envolve a escola, os professores, os alunos, os pais, a comunidade, que interagem no processo de ensino). (LIBÂNEO, 1994, p. 222).

Dessa forma, podemos concluir que ação de planejar envolve vários sujeitos, que estão interligados e que agem na sociedade a fim de enfrentar problemáticas (C) (1) Perspectivas em Diálogo, Naviraí, v. 8, n. 16, p. 72-86, jan./abr. 2021. 
que surgem no dia a dia, uma vez que esse processo de ensinar e aprender, não é algo estático, mas algo dinâmico que envolve a família, os professores, os alunos e a comunidade. Nesse percurso de planejar se faz necessário que o professor esteja sempre em constante formação, buscando cursos, aperfeiçoamentos, especializações que permitam refletir sobre a prática e praticar o que se reflete. Numa tríade de reflexão, ação e reflexão. Numa linguagem divertida o pesquisador Celso Antunes (1994), diz que existem: professores e professauros; sinalizando para o professor que adota uma prática engessada que não entende seu contexto para pensar possibilidades frente às questões do cotidiano. De acordo com Haydt (2006, p. 7879) o professor exerce um papel fundamental na mediação dos conhecimentos sistematizados, já que esse vínculo professor-aluno pode trazer ganhos para todos, cabendo ao professor refletir "sobre este fato, extraindo dele conclusões de ordem prática que o ajudem a aperfeiçoar sua atuação docente".

Durante nossa trajetória escolar é bem comum encontrarmos essa situação, às vezes nem temos tanta afinidade com os conteúdos de determinada disciplina, mas a forma como o professor desenvolve e mediatiza os conteúdos faz toda a diferença, quantas histórias não ouvimos de pessoas que odiavam tal assunto, mas quando encontraram um professor que soube dialogar sobre os conteúdos criaram afinidades e interesses pelos assuntos ministrados. E isso está relacionado com a didática, sendo que no planejamento pedagógico, podemos oportunizar boas experiências e a troca de saberes entre os docentes, o que tem dado certo? O que precisa ser mudado? Por que determinado aluno não consegue tantos avanços? Estou ouvindo os alunos? Todas aprendem de uma só forma? Nesse diálogo, boas ideias podem surgir que darão início a novas práticas que permitirão avanços significativos, tentativas alicerçadas em planejamento possibilitam um bom desenvolvimento.

O planejamento funciona como uma bússola para guiar as aulas que serão ministradas, sendo que nesse percurso pensar a didática tem relação a direção que se busca ofertar nas aulas. Conforme Libâneo (2010, p. 144): 
direção e organização do ensino e da aprendizagem pelos quais se assegura a mediação docente de objetivos, conteúdos, métodos, em vista da efetivação da assimilação consciente de conhecimentos. Nesse sentido, define-se como direção do processo de ensinar, no qual estão envolvidos, articuladamente, fins imediatos (instrutivos) e mediatos (formativos) e procedimentos adequados ao ensino e à aprendizagem. Ou seja, a atividade teórica e a atividade prática que se unificam nas práxis de quem ensina.

Esse processo de aprender e ensinar não diz respeito apenas do professor que ensina e do aluno que aprende, mas ambos aprendem e ensinam, buscam em comunhão criar possibilidades para provocar mudanças na sociedade. Conforme Libâneo (2011, p. 128):

Através do ensino criam-se as condições para a assimilação consciente e sólida de conhecimentos, habilidades e atitudes, nesse processo o aluno forma suas capacidades e habilidades intelectuais para se tornarem, sempre mais, sujeitos da própria aprendizagem. Ou seja, a matéria a ser transmitida proporciona determinados procedimentos de ensino, que por sua vez, levam as formas de organização do estudo ativo dos alunos.

Dessa forma, se faz necessário que no planejamento se pense formas para que os alunos estabeleçam uma relação com o saber, que este crie conexões e comece a perceber qual a importância do conhecimento para sua vida, o que este pode fazer como sujeito ativo na sociedade, aonde pode intervir e propiciar mudanças. A respeito dessa relação pedagógica Charlot (2000, p. 67 e 68) vem nos auxiliar:

Aprender, sob qualquer figura que seja, é sempre aprender em um momento de minha história, mas, também, em um momento de outras histórias: as da humanidade, da sociedade na qual vivo, do espaço no qual aprendo, das pessoas que estão encarregadas de ensinar-me. A relação pedagógica é um momento, isto é, um conjunto de percepções, de representações, de projetos atuais que se inscrevem em uma apropriação dos passados individuais e das projeções - que cada um constrói - do futuro.

Assim, aprender e ensinar é uma relação viva, ativa, dinâmica, por isso tão importante na construção do conhecimento, à medida que dialogamos com o passado, com os saberes construídos, estamos atuando no presente, mas também propiciando novos olhares para o futuro. Dessa forma, planejar envolve também pensar meios de alterar a realidade em que estamos.

\section{Caminhos teórico-metodológicos da pesquisa}


O percurso metodológico deste artigo fundamentou-se na abordagem qualitativa do tipo estudo de caso. Como técnicas para coleta de dados, utilizamos a observação, a pesquisa documental, entrevista semiestruturada e uma palestra que ocorreu no planejamento sobre a educação emocional como componente curricular da Educação Básica da rede Estadual de Ensino da Paraíba. Consoante Brandalise (2011), as técnicas elencadas devem estar em conformidade com as dimensões e indicadores propostos no estudo. A autora afirma que nenhuma técnica é completa sozinha, por esta razão se faz necessário escolher outros instrumentos que se complementam a fim de alcançarmos os objetivos propostos.

Conforme Yin (2015) o estudo de caso contribui para a compreensão dos fenômenos individuais, grupais, organizacionais, sociais e políticos. Como também, investiga um fenômeno contemporâneo em profundidade, considerando seu contexto e contribui para a formação do pesquisador, já que enfoca temas em que o pesquisador tem pouco ou nenhum controle. Em um primeiro momento, realizamos a observação da escola pesquisada, conhecendo seus espaços, seus sujeitos, seus momentos de integração com a comunidade e realizamos um planejamento pedagógico voltado para reflexão acerca da educação emocional dos nossos estudantes. Yin (2016) fala que a observação é um valioso instrumento para coletar dados, já que o que o pesquisador vê e sente, não sendo filtrado por aquilo que os outros falam. Logo, o ato de observar inclui as características de cada pessoa, as interações, as ações humanas ou mecânicas e as circunstâncias físicas.

No intuito de conhecermos a história da escola, seu corpo docente, discente e os dados de evasão e repetência, realizamos uma pesquisa documental no projeto político pedagógico da escola, nos projetos interdisciplinares e na instrução normativa da Secretaria de Educação e Cultura para as escolas. Nesse sentido, Yin (2016) afirma que os documentos, registros arquivais e artefatos contribuem para uma variedade de dados verbais, numéricos, gráficos e pictóricos. Para a fase de análise de dados, seguimos os passos indicados por Yin (2016), no tocante à sistematização dos dados, composição, decomposição, interpretação e análises.

No que concerne ao seu corpo discente é constituído majoritariamente por alunos do próprio bairro dos Novais, mas também possui alunos dos bairros: Cruz das Armas, Oitizeiro, Bairro das Indústrias e Jardim Planalto, chegando à escola a pé 
ou de motocicleta ou carro, acompanhado dos pais ou familiares. A respeito dos números de evasão escolar e reprovação, nos últimos dois anos (2018 e 2019), o índice de evasão foi de zero porcento e oito reprovados, tanto em 2018, como em 2019, sendo o maior índice de reprovação no $3^{\circ}$ ano, o que indica a sugestão de políticas, como a do Pacto Nacional de Alfabetização na Idade Certa, em que o ciclo de alfabetização é iniciado no $1^{\circ}$ ano, aprofundado no 20 ano e consolidado no $3^{\circ}$ ano, ao final desse ciclo os alunos que não foram alfabetizados podem ser reprovados, já que se considera que no $1^{\circ}$ e $2^{\circ}$ anos o processo de alfabetização está em andamento.

A escola encontra-se na $11^{\circ}$ posição na rede municipal com relação aos resultados do Índice de Desenvolvimento da Educação Básica (IDEB), com o índice de 5,2\% no ano de 2017, no ano de 2019 ficou entre as doze escolas do município que alcançaram as metas de leitura do Programa Educar Pra Valer, desde 2009 com a criação do prêmio escola nota dez, que busca valorizar os profissionais da educação do município, através de uma bonificação denominada $14^{\circ}$ salário, a escola já recebeu por oito vezes a nota máxima.

Seu corpo docente é constituído por quatro professoras efetivas, oito prestadoras de serviço, dois professores de educação física com regime de prestação de serviço, como a professora de ensino religioso e o professor de artes. Possui dois gestores, um para parte administrativa e um responsável pela parte pedagógica. Integra a equipe pedagógica: supervisora, orientadora e assistente social.

Em 2019 a escola contava com 308 alunos, sendo que 67 estavam matriculados na educação infantil, 229 no ensino fundamental e 12 no projeto de aceleração do saber. Segue de maneira sintética a organização das turmas da escola, conforme Quadro 1: 


\begin{tabular}{|l|l|l|}
\hline \multicolumn{1}{|c|}{ Qurma } & \multicolumn{1}{c|}{ Turno } & $\begin{array}{c}\text { Quantidade } \\
\text { de alunos }\end{array}$ \\
\hline Pré I & Tarde & 26 \\
\hline Pré II & Tarde & 41 (2 turmas) \\
\hline $1^{\circ}$ ano & Tarde & 47 (2 turmas) \\
\hline $2^{\circ}$ ano & Manhã & 25 \\
\hline $2^{\circ}$ ano & Tarde & 26 \\
\hline $3^{\circ}$ ano & Manhã & 22 \\
\hline $3^{\circ}$ ano & Tarde & 27 \\
\hline $4^{\circ}$ ano & Manhã & 22 \\
\hline $4^{\circ}$ ano & Tarde & 25 \\
\hline $5^{\circ}$ ano & Tarde & 45 \\
\hline Acelera & Manhã & 12 \\
\hline
\end{tabular}

Fonte: Secretaria da escola (2019).

No momento de planejamento pedagógico trouxemos uma palestra sobre competências socioemocionais que ocorreu em agosto de 2019 e contou com os gestores da escola, docentes e especialistas, sendo esses os sujeitos da pesquisa e partir de uma exposição dialogada, utilizando o aplicativo "mentimeter" que possui o objetivo de criar um feedback em tempo real, criando também a possibilidade de aprofundarmos temas e identificarmos a compreensão dos sujeitos participantes. Como questões norteadoras, para esse processo fizemos perguntas bem amplas para assim refletirmos com os sujeitos, tais como: Em sua opinião, a qualidade da educação pública tem melhorado nos últimos anos? Qual a área que mais precisa avançar em termos de qualidade? O que pudemos fazer ou o que estamos fazendo para as melhorias na qualidade da educação básica?

As respostas se aglutinaram em três categorias base: participação da família no processo formativo; estrutura física no estabelecimento de ensino e o uso de tecnologias no processo de ensino-aprendizagem. Esse momento foi muito rico já que proporcionou uma visualização das respostas de todos e uma discussão em volta desses temas. Após esse momento fizemos uma entrevista, tendo em vista identificarmos o tempo da docência e na área escolar e o vínculo empregatício. 


\section{Participação da família no processo formativo}

A participação da família na escola foi apontada pelos sujeitos pesquisados como a área em que há mais necessidade de avanços no caminho que leva à uma educação de qualidade. Foi unânime entre os professores, gestores e especialistas, o entendimento de que o êxito do processo pedagógico escolar passa necessariamente pelo acompanhamento efetivo dos familiares do estudante em âmbito doméstico.

A relevância dada pelos educadores ao processo formativo enquanto ação compartilhada com a família ganha destaque nos debates educacionais. Parece ser consensual entre os educadores a concepção de que a família exerce um papel fundamental na formação dos estudantes e que, sem o auxílio dos familiares no processo formativo, os professores estariam desenvolvendo um trabalho pedagógico importante do ponto de vista instrucional, mas inócuo no que se refere ao viver em comunidade.

Ao discorrer sobre a importância da família no processo de EnsinoAprendizagem, De Lima (2020, p.52) ratifica a necessidade "da família estar em torno da escola e ter uma participação ativa", algo que está para além de matricular os filhos em uma escola e transferir integralmente para os professores a responsabilidade pelo processo formativo como um todo, as próprias legislações como a Lei de Diretrizes e Bases da Educação no 9.394/1996 e o Estatuto da Criança e do Adolescente no 8.069 de 1990, apontam para a participação da família e da sociedade no processo educativo, ratificando em lei a participação familiar como relevante na aprendizagem das crianças e adolescentes.

Observar o caderno, auxiliar na execução do "dever de casa", estimular o hábito da leitura são algumas das ações que podem ser exercidas pelos pais e que certamente colaboram com o processo pedagógico. Obviamente, para exercer atividades dessa natureza os pais precisam possuir interesse e gozarem de certo nível instrucional, o que nem sempre ocorre, principalmente entre as famílias mais desfavorecidas economicamente. Tal fato, não exime a participação da família na vida escolar dos educandos, já que em diálogo, família e escola podem criar mecanismos de ajuda mútua, a exemplo de irmãos mais velhos, primos, tios que podem ajudar nos deveres de casa... e na própria sala de aula, pode-se pensar em 
metodologias de adote um colega, em que os próprios alunos ajudem uns aos outros, fortalecendo a coletividade da turma.

É evidente que os jovens estudantes reproduzem comportamentos assimilados domesticamente quando adentram o espaço escolar, se torna natural, por exemplo, o fato de que "Se os jovens não aceitam a autoridade dos pais, acabam por recusar a autoridade dos professores" (FERNANDES, p. 263, 2017), e, nesse contexto, a escola vê-se obrigada a cumprir uma dupla função, a saber: socializar o saber historicamente produzido (SAVIANI, 2011) e educar para a vida em sociedade, não necessariamente nessa ordem.

\section{Estrutura física do estabelecimento escolar}

Um segundo fator apontado pelos professores pesquisados como diretamente relacionado ao êxito do processo pedagógico refere-se à infraestrutura apresentada pelo estabelecimento escolar. As condições oferecidas aos estudantes, em termos de espaço físico propício ao bom desenvolvimento do processo pedagógico, foram apontadas como elemento de fundamental importância para que ocorra efetiva aprendizagem.

Sentir-se confortável em um espaço físico é condição básica para uma aprendizagem eficaz, de tal forma que "Alguns estudos já comprovam que condições desfavoráveis de conforto ambiental são causa de mau desempenho dos alunos" (BELTRAME e MOURA, p.5, 2009). Temperatura desagradável, espaço físico reduzido e configuração inadequada da sala de aula são algumas das condições consideradas impróprias a um processo educativo fecundo.

O fato é que as construções escolares seguem "Projetos arquitetônicos visivelmente padronizados, não necessariamente coerentes com as necessidades pedagógicas e/ou ergonômicas dos seus usuários" (SILVA; LIMA; ALMEIDA, p. 616, 2020), são construções que, por vezes, ignoram fatores como ventilação, iluminação e acessibilidade.

Vale salientar, que pelas observações feitas, notamos que a escola estava passando por um processo de reforma, com o redimensionamento de salas de aula, para a biblioteca, sala de apoio pedagógico, junção de turmas e utilização do recreio coberto para a ministração das aulas. 
Nesse contexto, o professor vê-se diante de uma conjuntura complexa em que o conteúdo precisa ser ministrado, mas as condições para fazê-lo são adversas. Desse modo, como esperar que os estudantes obtenham bons desempenhos? Quais estratégias podem ser desenvolvidas a fim de dirimir tais problemas?

Pois bem, torna-se difícil encontrar uma resposta para indagação feita no parágrafo acima, ainda mais quando nos deparamos com os meios de difusão de informação que, de tempos em tempos, divulgam matérias em que abordam a situação de algumas escolas do norte do Brasil, nas quais, aos estudantes não é concedido nem ao menos o direito de fazer uso de um banheiro decente, utilizar água encanada e gozar de equipamentos de recreação.

Firma-se, portanto, uma estreita relação entre fracasso escolar e estrutura física das instituições de ensino, conforme apontam os educadores pesquisados. Dessa forma, políticas públicas que almejem processos pedagógicos exitosos não podem deixar de contemplar aspectos físicos dos espaços escolares.

\section{O papel das tecnologias digitais no processo de ensino-aprendizagem}

As tecnologias ocupam atualmente espaço importante no cenário educacional, elas são "oportunidades aproveitadas pela escola para impulsionar a educação, de acordo com as necessidades sociais de cada época" (KENSKI, p.101, 2012). Seja auxiliando o ensino presencial ou de maneira autônoma como ocorre na educação a distância, os recursos tecnológicos, principalmente as renomadas Tecnologias Digitais da Informação e Comunicação (TDIC) tornam-se cada vez mais relevantes no campo pedagógico.

É bem verdade que em uma sociedade onde as tecnologias ocupam um espaço tão significativo, a escola não poderia ser uma instituição neutra, de modo que, a ela cabe uma reflexão acerca da adequação das metodologias de ensino para a formação de sujeitos na, assim denominada, sociedade do conhecimento.

Nesse contexto, segundo Moran (2013, p.12) "nosso papel fundamental na educação escolar é de ser mediadores interessantes, competentes e confiáveis", de tal forma que, aos educadores cabem compreender a mudança que consiste em sair da condição de únicos detentores do saber para a posição de mediadores. 
Os sujeitos pesquisados compreendem a necessidade da inserção das tecnologias digitais no processo de ensino-aprendizagem, contudo, nada relatam acerca da mudança da postura do professor. Pode-se apreender de tal constatação que para alguns professores o simples uso da tecnologia já promoveria bons resultados pedagógicos sem que para isso fosse necessária uma mudança comportamental dos docentes.

É urgente a necessidade de compreensão que os professores podem e devem fazer uso das tecnologias digitais e que elas são fatores fundamentais para o êxito dos estudantes no processo de ensino-aprendizagem. Todavia, é preciso que os docentes percebam o seu papel nesse cenário que, se não deve passar pela supervalorização das TDIC, também não pode caminhar rumo à negação destas.

\section{Considerações finais}

O texto trouxe o debate do planejamento pedagógico como importante ferramenta no dia a dia da escola, não somente para os professores, no que diz respeito a didática para ministrar os conteúdos, mas também para os gestores que podem identificar pelas narrativas dos docentes pontos fracos, que podem ser resolvidos com o diálogo com toda a comunidade escolar, ensejando novas práticas que possibilitarão melhorias como um todo, mas também os pontos fortes, as potencialidades que a escola apresenta e que podem facilitar no alcance de metas. Cabe ressaltar, que as soluções não se dão de maneira imediata, como um passe de mágica, mas essas são construídas no cotidiano da escola e como as sementes plantadas no solo, possuem um tempo para germinar e cuidados para que isso ocorra.

Ao final, vemos que diante de questões tão amplas, os sujeitos apontaram três fragilidades: a participação da família, a infraestrutura e o uso das novas tecnologias. Fica como sugestão, particularmente para essa instituição escolar, a partir desse diagnóstico, pensar meios de enfrentar essas problemáticas, quais os sujeitos que podem contribuir para essas melhorias e a realização de metas em torno dessas questões. 


\section{REFERÊNCIAS}

BELTRAME, Mauria Bontorin; MOURA, Graziella Ribeiro Soares. Edificações escolares: Infra-estrutura necessária ao processo de ensino e aprendizagem escolar. Travessias, v.3 n.2, 2009. Disponível em http://erevista.unioeste.br/index.php/travessias/article/view/3378 Acesso em 20: fev 2020.

DE LIMA, Andréia Lobo Moreira. A importância da participação da família no processo de ensino-aprendizagem. Revista Internacional de apoyo a la inclusion, logopedia, sociedad y multiculturalidad, v.6. n.1, p. 49-61, 2020. Disponível em https://revistaselectronicas.ujaen.es/index.php/riai/article/view/5198/4583 Acesso em: 18 fev 2020.

FERNANDES, Antonio Teixeira. Sociedade, família e escola. Sociologia: Revista da Faculdade de Letras da Universidade do Porto, v.17, p. 253-265, 2017. Disponível em https://ojs.letras.up.pt/index.php/Sociologia/article/view/2352/2153 Acesso em: 18 fev 2020.

KENSKI, Vani Moreira. Educação e Tecnologias: o novo ritmo da informação. Campinas, SP: Papirus, 2012.

LIBÂNEO, José Carlos. Didática. São Paulo: Cortez, 1994.

LIBÂNEO, José Carlos. Pedagogia e pedagogos, para quê? 12. ed. São Paulo: Cortez, 2010.

LUCKESI, Cipriano Carlos. Avaliação da aprendizagem escolar: estudos e proposições. São Paulo: Cortez, 2011.

MORAN, José Manoel. Ensino e Aprendizagem inovadores com apoio de tecnologias. In: BEHRENS, Marilda Aparecida; MASETTO, Marcos Tarcísio; MORAN, José Manoel. Novas tecnologias e mediação pedagógica. Campinas, SP: Papirus, 2013.

SAVIANI, Dermeval. A nova lei da educação. Campinas, SP: Autores Associados, 1997.

SAVIANI, Dermeval. Pedagogia Histórico-Crítica: Primeiras aproximações.

Campinas: Autores Associados, 2011.

SILVA, Jaciel Guilherme da; LIMA, Conceição Maria Dias de; ALMEIDA, Cláudia Cristina Rêgo. Arquitetura e escola: uma abordagem do espaço físico educacional colaborador dos processos de ensino. Diversitas Journal, v. 5, n.1, p. 615-629, 2020. Disponível em

https://periodicos.ifal.edu.br/diversitas_journal/article/view/1026 Acesso em: 20 fev. 2020. 
Recebido em: 26 de setembro de 2020.

Aceito em: 28 de outubro de 2020.

Publicado em: 05 de janeiro de 2021. 